\title{
Abstracting the Set: Monet's Cathedrals and Stable Mental Concepts from Serial Pictorial Artworks
}

Jason Kass ${ }^{1}$, Beth Harland ${ }^{2}$ and Nick Donnelly ${ }^{3}$

${ }^{1}$ Winchester School of Art, University of Southampton, Park Ave, Winchester SO23 8DL

${ }^{2}$ Lancaster Institute for the Contemporary Arts, Lancaster University, Bailrigg, Lancaster LA1 $4 Y W$

${ }^{3}$ Centre for Visual Cognition, Dept of Psychology, University of Southampton, University Rd, Southampton SO17 1BJ

Corresponding Author:

Jason Kass

Winchester School of Art

University of Southampton

Park Ave

Winchester SO23 8DL

e-mail: j.m.kass@soton.ac.uk

tel: +447738159547

Abstract:

The ability to form stable mental representations (or concepts) from a set of instances is fundamental to human visual cognition and is evident across the formation of prototypes, from simple pseudo-random dot patterns through to the recognition of faces. In this paper we argue that the cognitive and perceptual processes that lead to the formation of stable concepts are also important in understanding spectatorship of a certain class of serial artworks that are composed of multiple discrete but related pictures. This article considers the processes that enable the formation of stable mental representations in relation to a series of paintings of Rouen Cathedral by Claude Monet. The implications of understanding these processes for the spectatorship of this class of serial artworks are discussed.

\section{Introduction}

The typical and popular notion of an artwork is a single picture. To understand this 'masterpiece model' one need only think of Da Vinci's Mona Lisa hanging in isolation behind shatterproof glass and the crowds that queue en masse to catch a glimpse. In this 
model, individual pictures are experienced and understood by viewers autonomously in a direct and spontaneous manner. However, within the history of art there have been many occasions when artists have eschewed the masterpiece model to produce multiple pictures displayed together to create meaning. On these occasions the impact of the artworks, derived from the individual elements taken as a set, provides an experience altogether different from that offered by responding to autonomous single pictures.

Sets of related images, or series, come in two broad classes. In one class, pictures are temporally connected through a developing narrative. Figure 1 presents two of five paintings from Thomas Cole's Course of Empire (1833-36). Cole's canvases depict a civilisation's rise and fall through a cycle of prosperity and demise. The first, The Savage State, makes reference to a time before the onset of empire, while the final picture, Desolation, portrays a similar view after the empire's downfall. Through the comparison of iconographic elements within the series the full meaning of the work can be gleaned. Cole was not an innovator in this sense and in many centuries prior artists relied on sequences of pictures to tell stories or communicate morality. Religious narrative was explored in Roman and Byzantine frescoes and continued to be developed in Renaissance painting, for example with Titian's celebrated Old Testament cycle. In a temporally narrative series, the individual pictures can be valued along the traditional masterpiece model but it is when viewed and appreciated as a set that the full meaning becomes evident.
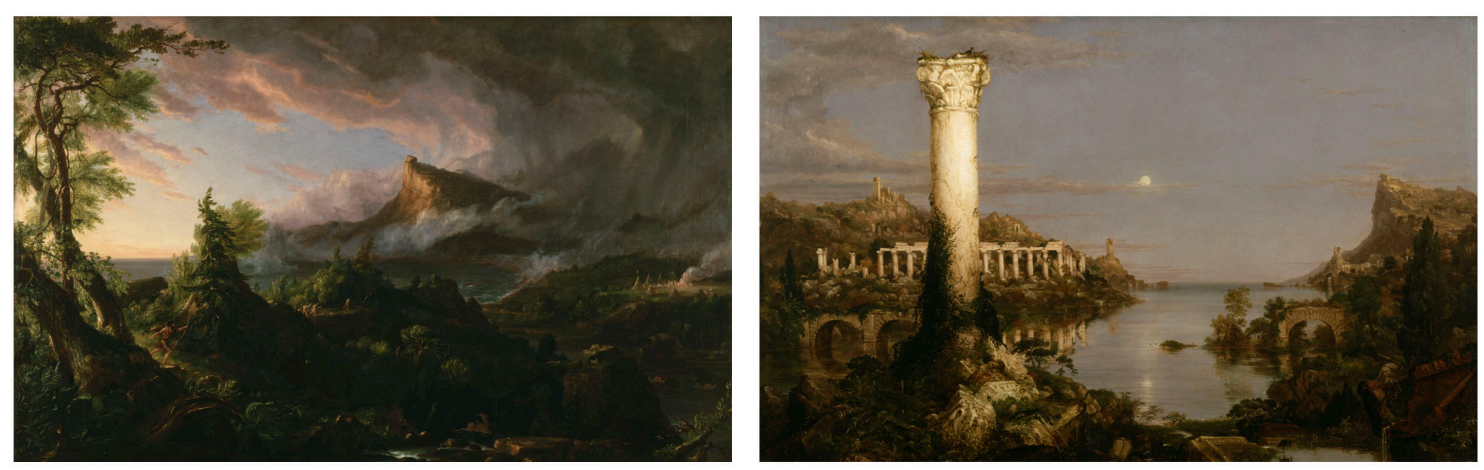

Figure 1. Two out of five canvases from Thomas Cole's narrative artwork Course of Empire (1833-36): (left) The Savage State; (right) Desolation. Collection of the New York Historical Society.

While important, series with a temporal narrative structure, and the cognitive and visual 
processes used to understand them, are not the focus of the present paper. This article is concerned with another kind of seriality. In this second class, visual elements are repeated from one picture to the next resulting in either pure repetition (identical instances) or compositionally stable pictures where the structure repeats despite descriptive changes. Importantly, in the first class, the multiple pictures comprise 'a series of artworks' whereas in the second class the set of pictures can effectively be described as 'a serial artwork'. The origins of this second class can be traced to Claude Monet's painting projects late in the Nineteenth Century including his haystacks, water lilies, and views of the Thames. In Monet's series, he painted multiple canvases of similar size and composition, varying the colour and tonality of each picture to reflect a particular time of day and weather condition. The idea of a serial artwork became established in the mid-Twentieth Century, a good example of this being Homage to the Square by Joseph Albers. Homage to the Square is a serial artwork comprising coloured inset squares repeating in the same composition across instances in different combinations of hue, saturation, and luminosity. Around the same time, Andy Warhol created his notorious Campell's Soup Cans, a serial artwork consisting of thirty-two paintings of the American food product including all flavour varieties in a compositionally consistent manner.

Anne Craven and Peter Dreher are contemporary artists whose work also falls into the second class of seriality. Craven, for example, paints multiple 'moonscapes', constraining the size and shape of each canvas while varying the position and phase of the moon (Fig. 2). She has exhibited her moonscapes in various configurations in groups as large as four hundred. Since 1974, Dreher has made thousands of paintings repeating a single drinking glass against a non-descript background. The size and composition of each painting is identical, revealing minute differences in colour and detail reflected in the glass. Damien Hirst has taken a similar approach in his Spot Paintings, nearly fifteen hundred canvases of coloured dots arranged in grid patterns on white backgrounds. 

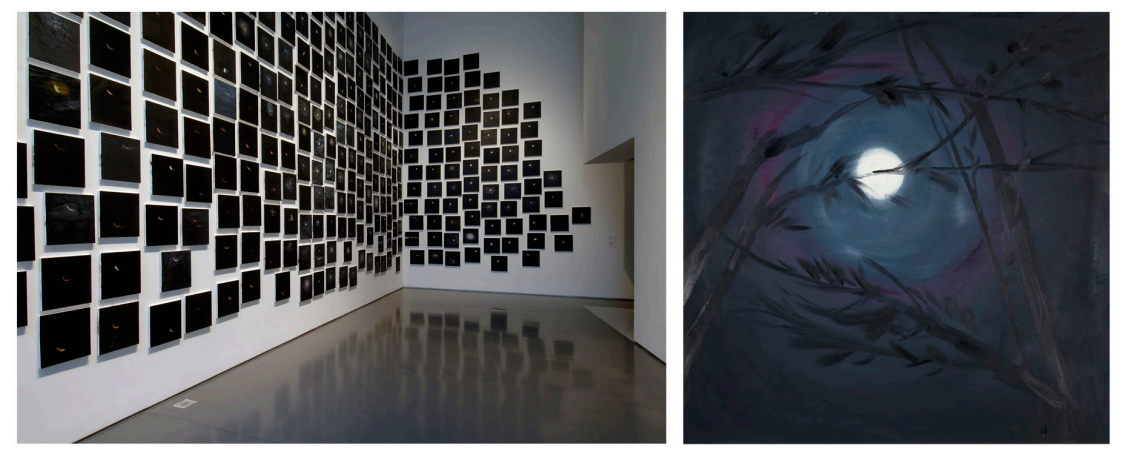

Figure 2. The picture on the left shows a serial artwork by Ann Craven, Moon (400 Copies), exhibited at Contemporary Art Center Cincinnati in 2006. On the right is Full Lover's Moon (July 18, 2008) $\# 8$ an example of an individual painting from a later serial artwork comprising multiple canvases. Courtesy of the artist and Maccarone Gallery, New York.

The second class of serial artworks, starting with Monet and continuing to the present day, is the focus of discussion in this paper. Characterized by repetition and deviations or transformations from a common pictorial basis, this class can include several to thousands of instances that are displayed together. Whereas explanations for Monet's seriality have typically been positioned in terms of the concurrent emergence of technological modes of reproduction (Sieberling, 1981) and cinema (Levine, 1978), other examples of seriality within this class have been explained with reference to mathematics (Bochner, 1967, 1995) or consumerism and the mundane (Dyer, 2004). Without discounting these and other existing theories on the impulse towards seriality, this article reconsiders the phenomenon in terms of the cognitive and perceptual predisposition to create a stable mental representation from a variable set of instances and resulting implications for the beholding of serial artworks.

\section{Stable Visual Representations}

Having established that serial artworks offer a beholder multiple related instances rather than a single authoritative picture, this section will consider the human cognitive and perceptual processes that are well suited to spectatorship of this kind. The goal of creating stable concepts applies in terms of integrating information across saccades (eye movements) to represent scenes and mental representations of concepts and occurrences stored in memory. As with serial artworks, human visual cognition and perception must account for 
both individual episodes and general concepts extracted from those episodes considered together. Stability is contributed to by perceptual processes that define invariant properties across images (see Wagemans et al., 1996, 1997). In addition, and in particular the cases we consider in depth here, stability refers more to establishing relationships across changing colours, luminance and textures.

The abstraction of stable concepts from sets of instances is often discussed in terms of exemplars and prototypes. In prototype-based models (Posner and Keele, 1968) the information consistent across exemplars (instances) must be identified, abstracted, and stored as a prototype during learning. Exemplar-based models (Hintzman, 1984, 1986, 1988) suppose that every instance of a category is stored and that abstraction takes place during the retrieval process. Hintzman suggests that during retrieval the cognitive system must create a meaningful and stable visual representation by consulting individually-stored traces in tandem. The traditional dichotomy of prototype versus exemplar models has recently been challenged in the literature, for example with the varying abstraction model of categorisation (Vanpaemel and Storms, 2008) which posits a spectrum and allows for partial abstraction (i.e. a combination of exemplars and prototypes being stored). For our purposes it is not necessary to resolve the debate but rather to recognise that proper categorisation of concepts in a dynamic world relies, to some degree, on abstraction.

Abstracting a concept or robust representation from a set of variable instances is evidenced clearly in the case of face recognition. For recognition purposes it is crucial that cognitive and perceptual processes can account for the visual differences inherent in each successive encounter with a particular face. Correct identification is contingent on overcoming the superficial visual differences arising from lighting conditions or changes in facial hair, hairstyle or makeup, resulting from a set of varied encounters over time. It has been recognised for some time that structural codes from faces must be harnessed towards the abstraction of a pragmatic visual representation (Bruce and Young 1986). More recent discussions surrounding stability from variation and the formation of robust visual representations have focused on averaging techniques as a basis for the formation of prototypes from a set of variable exemplars (Benson and Perrett, 1993). Research has been 
extended to examine the power of averages by looking at computational systems (Burton et al., 2005) that use averaging algorithms to improve face recognition, with insight gained into similar mechanisms within human visual cognition.

Figure 3 demonstrates that averaging removes the superficial differences between instances in order that the essential characteristics remain. Averaging across instances retains information useful for identification and eliminates extraneous details (Young and Bruce, (2011), ascertaining something of the essence of a person's appearance (Jenkins et al., 2006). The variation offered by repeated exposure to a stimulus (i.e. a person's face) contributes to the formation of a robust visual representation, and increased exposure strengthens familiarity (Burton et al., 2005, 2011) in that it provides further opportunity for variation to be identified and for useful information to be gleaned. In other words, the more variation that exists within a set of instances, the easier it will be to identify what visual information persists and to form a stable concept as a result (Bruce, 1994).
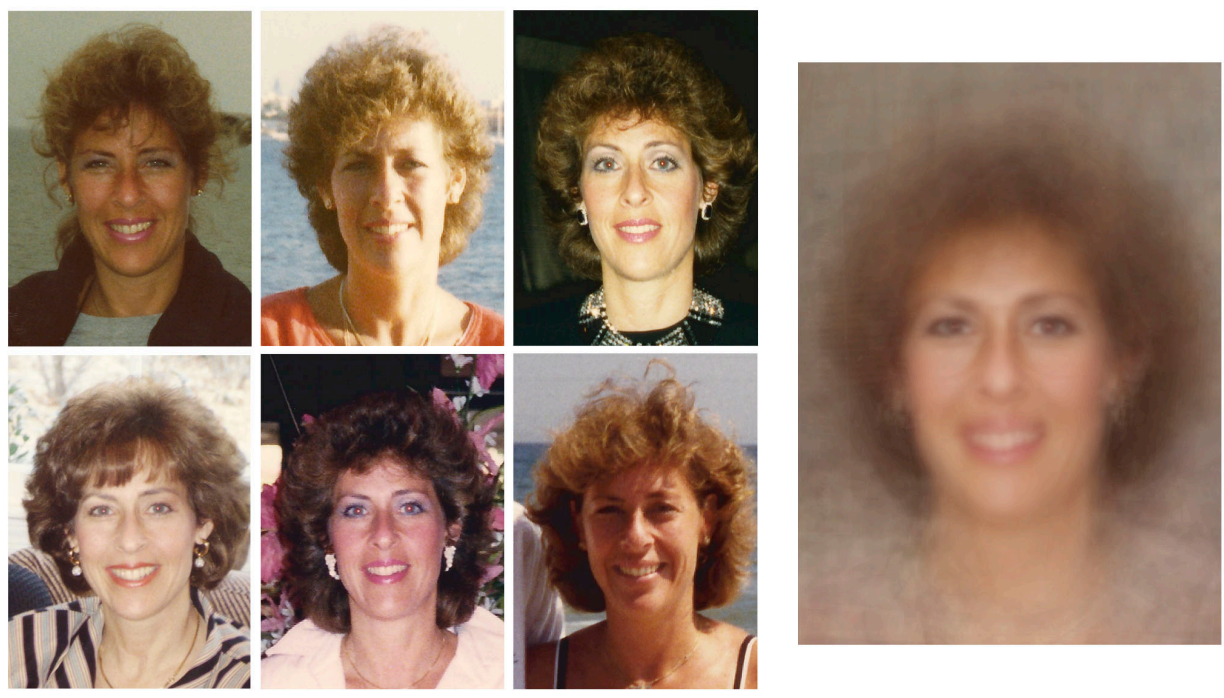

Figure 3. An illustration of the power of averaging in creating a stable visual representation, the larger image on the right is an average of nearly forty constituent images some of which are shown on the left. The set of images is currently the focus of practice-led research into relational meaning in pictorial art being undertaken by the first author (JK). Note that artworks resulting from this practice-led research were part of an exhibition at $5^{\text {th }}$ Base Gallery, London in November 2013.

\section{Monet's Cathedrals}


The relationship between exemplars and prototypes within face recognition can be extended towards serial artworks. By extension, the highly visually varied encounters with a particular face become the discrete but related individual pictures that comprise a serial artwork.

Monet's series of paintings of the façade of Rouen Cathedral serve as a useful case study, not least for the similarity between faces and façades. In the series, Monet repeated and varied the motif across multiple canvases, resulting in nearly thirty paintings that share a similar composition yet differ substantially in colour and tone. It is well understood that Monet's interest in creating the series was based on his desire to represent the fleeting quality of visual experience and the momentary nature of perception. He recognised the impossibility of any single true depiction of the cathedral - "everything changes, even stone" (Bernier, 2007, p.73) - and endeavoured to paint the building in a variety of weather conditions and at different times of day. Monet realised (perhaps intuitively) that in order to explore what changed from one moment of perception to the next it was essential to apply constraints to what he put down on canvas (see Zeki, 1999 for a related discussion). To depict the cathedral through multiple canvases, Monet might have considered painting from a variety of viewpoints or focused on the building at large and also in fine detail. He also could have pursued temporal narrative in the series, but instead, he painted essentially the same view and scale within his compositions to map the changing qualities of his perceptual experience. Monet also understood the value of viewing the individual instances as part of a set, when he indicated that the canvases gain importance through comparison within the series (Levine, 1978). 

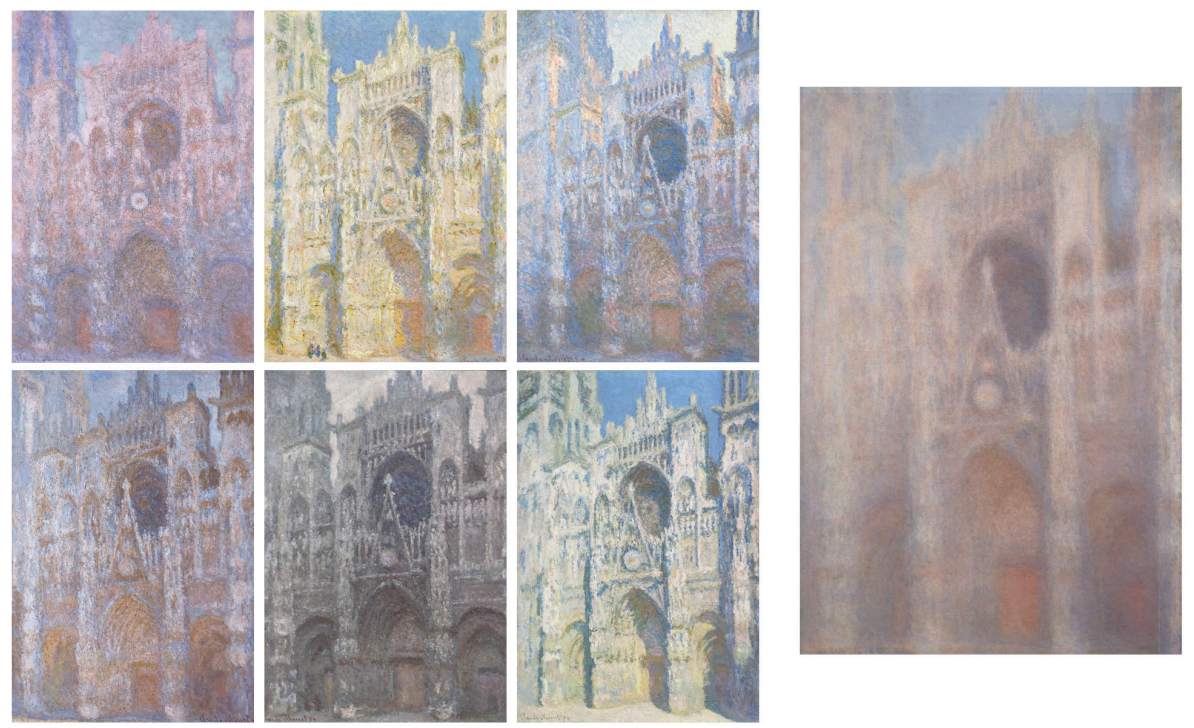

Figure 4. The average of a subset of instances from Claude Monet's Rouen Cathedral series (1892-94) created in Photoshop. The individual canvases on the left represent the variation amongst instances: clockwise from top left (i) Rouen Cathedral: Setting Sun (Symphony in Pink and Grey). National Museum Wales (ii) Rouen Cathedral: West Façade (Sunlight). National Gallery of Art, Washington DC. (iii) Rouen Cathedral: West Façade. National Gallery of Art, Washington DC. (iv) Rouen Cathedral: Harmony in Blue and Gold (Sunlight). (C) Musée d'Orsay, Dist. RMN-Grand Palais /Patrice Schmidt. (v) Rouen Cathedral: Harmony in Grey. (C) Musée d'Orsay, Dist. RMN-Grand Palais /Patrice Schmidt.(vi) Rouen Cathedral: Harmony in Blue (Morning Sun). (C) Musée d'Orsay, Dist. RMN-Grand Palais /Hervé Lewandowski.

As a result of having constrained his composition in terms of viewpoint and scale, the averaging process previously discussed in terms of face recognition can equally be applied to Monet's cathedrals. Figure 4 shows an average based on a subset of paintings from the series. As in the example using faces, the process of averaging removes the superficial qualities and depicts the cathedral stripped of any specificity. The process effectively undoes Monet's enterprise by taking discreet moments of perception and averaging them into an efficient and general concept of the cathedral. Whereas the individual paintings portray a generally discernable time of day and weather condition, it is harder to say the same where the average is concerned. Monet acknowledged the importance of the series being exhibited as a set and understood that the individual instances viewed together established a more meaningful experience for a spectator. What Monet likely did not grasp was the basis for the cognitive and perceptual processes responsible. There is no evidence that Monet comprehended, 
outright, that his approach to painting the cathedral would result in a more stable concept and robust mental representation of the cathedral in the minds of those viewing the series. Regardless, his innovation effectively broke with the history of pictorial art that preceded him and paved the way for future generations of artists to further exploit the cognitive and perceptual processes that underpin serial artworks. The implications of Monet's seriality within the history of art will be discussed in more detail in the following section.

\section{Discussion}

Monet's paintings deviated from previous examples of seriality in his use of constrained repetition across each picture. Monet's approach to his serial artworks influenced future generations of artists including Albers and Warhol and his influence can still be seen in the work of contemporary artists like Craven, and Dreher. Whereas existing theories regarding serial artworks focus on the social, technological, or philosophical underpinnings of their production, we have focused our attention on the implications for the spectator of serial artworks based on a fundamental attribute of human visual cognition. Central to our argument is the claim that humans create stable mental concepts from sets of related instances experienced over time and that serial artworks are no exception to this rule. Although not a central concern or intention for Monet at the time of their production, serial artworks like his paintings of Rouen Cathedral question the manner in which an artwork can be experienced. Unlike single pictures that are experienced in a direct and spontaneous manner, serial artworks comprising multiple discreet but related pictures are experienced indirectly via the formation of an abstracted mental concept of the artwork.

Art historical discourse tends to emphasize the contribution of Monet and his peers regarding artistic volition and a move away from mimetic painting that had dominated previous generations. Undoubtedly, the Impressionist approach to colour and the application of paint, and the underlying interest in visual perception, had significant implications for the development of abstraction in Western painting in the early Twentieth Century (see Thomson, 2000). Less attention, however, has been given to the manner in which Monet's serial artworks inadvertently questioned the nature of spectatorship by defying the notion of a 
single original picture and authorship in the way in which the set of instances prompt the formation of a mental concept in the mind of the spectator. According to this criterion, Monet's serial artworks can be thought of as displaying characteristics that relate to conceptual practices of the late twentieth century that “....redefined the conditions of receivership and the role of the spectator" (Buchloh, 1990, p.107).

In a conceptual work of art the concept or idea offered to the spectator is of equal or additional importance than notions of beauty or sensual experience. In 1967, Sol Lewitt, a pioneer of conceptual art practice noted that "Conceptual art is made to engage the mind of the viewer rather than his eye or emotions" $(1999, \mathrm{p} .15)$. Although there is no evidence that Monet intended to engage the mind rather than the eye (in fact the opposite is probably true), here we have argued that serial artworks like Monet's prompt mental processes to establish stability across their variations due to the nature of the human visual cognitive system. We suggest that the conceptual aspects of Monet's series are at least as important as their formal and material merits (of which there are many). What is particularly interesting about this assertion is that Monet and his Impressionist colleagues were notoriously criticised by the influential artist Marcel Duchamp for creating artworks deemed purely 'retinal' in nature.

Duchamp, most famous for introducing the Readymade artwork in the form of an upsidedown and signed urinal, was interested in artworks that went beyond the eye (i.e. beauty) and aimed for something more cerebral and concept driven (an obvious influence on Lewitt and his peers). Duchamp compared Monet and the Impressionists to house painters whose only interests were with colour and painting for painting's sake. Although Duchamp cannot be denied his significant influence on later developments in Conceptual Art, we believe Monet planted early seeds for such developments. To be bold, based on the premise put forth in this paper, the influence of Monet's seriality can even be extrapolated as an influence on relational aesthetics popularised towards the end of the Twentieth Century along with other forms of installation art. The distinctive character of the latter has been theorised in terms of the fact that "the ensemble of elements within [an installation], are regarded in their entirety as a singular entity" (Bishop, 2005, p.6). Similar language is used in a discussion of the former, which posits the artwork as "an ensemble of units to be re-activated by the beholder- 
manipulator (Bourriaud, 1998, p.20). In both cases the relationship between individual elements and the resulting mental concept contributes to the meaning and experience of the artwork, a claim we have applied to Monet's cathedrals.

We recognise that there are examples of painters prior to Monet who aimed to go beyond the purely 'retinal' (such as Cornelius Gijsbrecht and his Reverse Side of a Painting (1670) that depicted the back of a canvas in order to fool the viewer) and that any artwork is conceptual in that it involves mental processes in order to be understood. However, the conceptual inclination of serial artworks like Monet's is distinctive in its particular play to human perceptual and cognitive functioning. Unlike tromp l'oeil still life paintings which are still designed to be experienced directly and in the moment, serial artworks encourage the formation of concepts that transcend the physical presence of the paintings and that persist long after the viewing experience. These two modes of visual experience have been explained in terms of the "iconic" and the "conceptual" qualities that form a spectrum onto which any artwork can be mapped (Koenderink and van Doorn, 2013).

One should not dismiss Monet's, or any other artists use of seriality as being overtly conceptual or anti-aesthetic. In fact the same features responsible for driving the formation of mental concepts can be thought of in terms of their impact on the aesthetic experience of the viewer. There is literature surrounding the idea of the positive affect associated with stability from variation and the way that averages and prototypes result in a pleasurable sensory experience for a viewer. It is possible that viewer processing dynamics (Winkielman et al., 2003; Reber et al., 2004; Belke et al., 2010) and the impact of the 'mere exposure effect' (Zajonc, 1968) on perceptual fluency may contribute to an enjoyable response to repetition within serial art. The mere exposure effect refers to the positive response to a stimulus simply from having been exposed to it previously and can develop from instances that repeat or that share a common characteristic or underlying structure (Zizak and Reber, 2004). Positive affect can also be associated with the pleasure derived from problem solving, for example through the resolution of ambiguity. In terms of aesthetic appreciation, this idea has been elaborated by way of the 'aesthetic aha' (Muth and Carbon, 2013). Arguably, serial artworks provide an opportunity for the spectator to resolve the 'problem' of the relationships between 
instances and offer the possibility that the averaged mental prototype could be akin to a true Gestalt.

The notion of adaptation for aesthetic appreciation can also be informative in relation to serial artworks. Adaptation, whereby new visual information becomes habituated, has been discussed in terms of the dynamics of aesthetic appreciation and as a way of explaining changing artistic tastes from one period to another (Carbon 2011). For example, adaptation can help to explain how an innovation in style that is initially rejected can become favourable. French Impressionism demonstrates this quite well since Impressionist works of art initially repulsed and offended audiences whereas today they produce blockbuster exhibitions in major museums (for a related discussion see Cutting 2003, 2007). Artists who create serial artworks inadvertently provide fertile ground for adaptation indicating that beyond mere exposure effects, seriality might be effective in promoting an artist's visual brand.

In this paper we have proposed that artworks comprising multiple discreet but related pictures (serial artworks) may prompt the formation of stable mental concepts abstracted from relationships within the set. We have recognised that stability is first and foremost contributed to by perceptual processes that define invariant properties across instances. Using Monet's paintings of Rouen Cathedral as a case study, we have demonstrated that descriptive changes across instances that share a basic composition may lead to the formation of a robust representation resembling a mental prototype. We have suggested possible implications for the spectatorship of serial artworks based on cognitive and perceptual process that may impact on viewer processing dynamics. Future empirical work will be useful in determining a psychological reality to the experience of serial artworks both in terms of stable mental representations and in terms of processing fluency and positive affect.

\section{References}

Belke, B. et al. (2010) Cognitive Fluency: High-Level Processing Dynamics in Art Appreciation. Psychology of Aesthetics, Creativity, and the Arts, 4(4), pp.214-222. 
Benson, P.J. and Perrett, D.I. (1993) Extracting Prototypical Facial Images from Exemplars. Perception, 22, 257-262.

Bernier, R.R. (2007) Monument, Moment, and Memory: Monet's Cathedral in Fin de Siècle France. New Jersey: Associated University Presses.

Bishop, C. (2005) Installation Art. New York: Routledge.

Bochner, M. (1967) The Serial Attitude. Artforum, pp.28-33.

Bochner, M. (1995) Serial Art, Systems, Solipsism (1967). In G. Battcock, ed. Minimal Art: A Critical Anthology. Berkeley; Los Angeles: University of California Press, Ltd., pp. 92102.

Bourriaud, N. (1998) Relational Aesthetics. France: Les presses du réel.

Bruce, V and Young, A. (1986) Understanding face recognition. British Journal of Psychology, 77, pp.305-27.

Bruce, V. (1994) Stability from variation: The case of face recognition (the M . D . Vernon memorial lecture). The Quarterly Journal of Experimental Psychology, 47A(1), pp.5-28.

Buchloh, B.H.D., (1990) Institutions Conceptual Art 1962 - 1969 : From the Aesthetic of Administration to the Critique of Institutions. October, 55, pp.105-143.

Burton, A. M. et al. (2005) Robust representations for face recognition: the power of averages. Cognitive Psychology, (July), pp.1-35.

Burton, A.M. et al. (2011) Mental representations of familiar faces. British Journal of Psychology, 102(4), pp.943-58.

Burton, A. M. (2013) Why has research in face recognition progressed so slowly? The importance of variability. Quarterly Journal of Experimental Psychology, 66(8), pp.146785.

Carbon, C. (2011) Cognitive mechanisms for explaining dynamics of aesthetic appreciation. i-Perception, 2, pp.708-719.

Coplans, J. (1968) Serial Imagery. Pasadena: Pasadena Art Museum.

Cutting, J.E. (2003) Gustave Caillebotte, French Impressionism, and mere exposure. 
Psychonomic Bulletin \& Review, 10(2), pp.319-43.

Cutting, J.E. (2007) Mere Exposure, Reproduction, and the Impressionist Canon. In A. Brzyski, ed. Parison Canons. Durham and London: Duke University Press.

Dyer, J. (2004) The Metaphysics of the Mundane: Understanding Andy Warhol's Serial Imagery. Artibus et Historiae, 25(49), pp.33-47.

Fer, B. (2004) The Infinite Line: Re-making Art after Modernism. New Haven: Yale University Press.

Hintzman, D.L. (1984) MINERVA 2 : A simulation model of human memory. Behavior Research Methods, Instruments, \& Computers, 16(2), pp.96-101.

Hintzman, D.L. (1986) “Schema Abstraction” in a Multiple-Trace Memory Model. Psychological Review, 93(4), pp.411-428.

Hintzman, D.L. (1988) Judgments of frequency and recognition memory in a multiple-trace memory model. Psychological Review, 95(4), pp.528-551.

Jenkins, R. et al. (2006) Face Recognition from Unconstrained Images: Progress with Prototypes. In 7th International Conference on Automatic Face and Gesture Recognition (FGR06). Ieee, pp. 25-30.

Lewitt, S., (1999). Paragraphs on Conceptual Art. In A. Alberro \& B. Stimson, eds. Conceptual Art: A Critical Anthology. Cambridge: The MIT Press, pp. 12-16.

Levine, S.Z. (1978) Monet, Lumiere, and Cinematic Time. The Journal of Aesthetics and Art Criticism, 36(4), pp.441-447.

Muth, C. and Carbon, C.-C. (2013) The Aesthetic Aha: On the pleasure of having insights into Gestalt. Acta psychologica, 144(1), pp.25-30.

Posner, M.I. and Keele, S.W. (1968) On the Genesis of Abstract Ideas. Journal of Experimental Psychology, 77(3).

Reber, R. et al. (2004) Processing Fluency and Aesthetic Pleasure: Is Beauty in the Perceiver's Processing Experience? Personality and Social Psychology Review, 8(4), pp.364-82. 
Seiberling, G. (1981) Monet's Series. New York ; London: Garland.

Thomson, B. (2000) Impressionism: origins, practice, reception. London: Thames and Hudson.

Vanpaemel, W. and Storms, G. (2008) In search of abstraction: The varying abstraction model of categorization. Psychonomic Bulletin \& Review, 15(4), pp.732-749.

Winkielman, P. et al. (2003) The hedonic marking of processing fluency: Implications for evaluative judgment. In J. Musch \& K. C. Klauer (Eds.), The psychology of evaluation: Affective processes in cognition and emotion (pp. 189-217). Mahwah, NJ: Lawrence Erlbaum Associates, Inc.

Winkielman, P. et al. (2006) Prototypes are Attractive Because They Are Easy on the Mind. Psychological Science, 17(9), pp.799-806.

Young, A.W. and Bruce, V. (2011) Understanding person perception. British Journal of Psychology, 102, pp.959-74.

Zajonc, R.B. (1968) Attitudinal Effects of Mere Exposure. Journal of Personality and Social Psychology, 9(2(2)), pp.1-27.

Zeki, S. (1999) Inner Vision: An Exploration of Art and the Brain. Oxford: Oxford University Press.

Zizak, D.M. and Reber, A.S. (2004) Implicit preferences: The role(s) of familiarity in the structural mere exposure effect. Consciousness and Cognition, 13, pp.336-62. 